\title{
Perancangan Stetoskop Elektronik Portable
}

\author{
Gadang Hendra Prabowo, Muhammad Ridha Mak'ruf, Sumber, Liliek Soetjiatie, Bedjo Utomo \\ Jurusan Teknik Elektromedik Poltekkes Kemenkes, Surabaya \\ Jl. Pucang Jajar Timur No. 10, Surabaya, 60245, Indonesia \\ gadanghendra90@gmail.com,m.reedha@gmail.com, Sumber@poltekkesdepkes-sby.ac.id,
}

\begin{abstract}
Stetoskop merupakan alat medis akustik sederhana yang berfungsi untuk mendiagnosa suara dalam tubuh manusia. Tenaga medis sering menggunakan stetoskop akuistik ini untuk memeriksa suara jantung. Hasil pendengaran suara juga sangat subyektif, sehingga masing-masing orang bisa mengartikan berbeda. Dalam penelitian ini dibangun sebuah stetoskop elektronik untuk auskultasi jantung dengan tampilan TFT serta di rancang secara portable sehingga dapat mempermudah penggunaan alat. Stetoskop ini mampu mengambil data suara jantung pasien serta menampilkan data plot hasil pemeriksaan. Hasil data akan ditampilkan pada TFT serta ditampilkan juga nilai BPM dari pasien tersebut. Berdasarkan dari penelitian yang telah penulis lakukan, maka dapat diperoleh data plot suara jantung dengan menggunakan filter pada frekuensi cut off 56,679 $\mathrm{Hz}-88,646 \mathrm{~Hz}$ dan diperoleh nilai BPM dengan error terbesar $\pm \mathbf{0 , 7 2 \%}$. Nilai error alat masih dalam batas toleransi yaitu $<\mathbf{1 \%}$ berdasar ketetapan Balai Pengaman Fasilitas Kesehatan (BPFK). Desain Stetoskop Elektronik ini bersifat portable sehingga tidak memerlukan pc saat melihat tampilan plot sinyal jantung dan nilai bpm.
\end{abstract}

Kata Kunci-Stetoskop; Filter; Suara Jantung

\section{PENDAHULUAN}

Auskultasi adalah suatu teknik atau cara yang paling sering digunakan oleh tenaga medis dalam pemeriksaan awal pada pasien. Salah satu caranya adalah menggunakan alat yang bernama stetoskop. Stetoskop adalah alat medis akustik sederhana yang berfungsi untuk mendiagnosa suara dalam tubuh manusia. Tenaga medis sering menggunakan stetoskop akuistik ini untuk memeriksa suara jantung. Satu suara yang dapat dideteksi adalah suara yang terkait dengan aktivitas jantung memompa. Suara-suara mengklaim indikasi denyut jantung dan irama jantung. Suara ini juga berguna untuk memberikan informasi tentang efektivitas aktivitas pemompaan jantung dan hati katup. Sampai saat ini, instrumen clinicaly digunakan untuk mendeteksi suara jantung adalah stetoskop akustik [1] .Beberapa penelitian suara jantung telah banyak dilakukan, diantaranya adalah reduksi suara jantung dari instrumentasi akuisisi perekaman suara paru-paru pada anak-anak menggunakan butterworth band pass filter [2] .

Salah satu cara untuk mengetahui kondisi pasien adalah dengan mendengarkan suara dari dalam tubuh manusia, yaitu melalui suatu alat yang disebut stetoskop. Proses pemeriksaan suara respirasi atau detak jantung disebut auskultasi. Masalah yang terjadi pada auskultasi jantung menggunakan stetoskop konvensional yaitu noise lingkungan, kepekaan telinga, frekuensi dan amplitudo yang rendah, dan pola suara yang relatif sama. Hasil pendengaran suara juga sangat subyektif, sehingga setiap orang dapat mengartikan hasil yang berbeda). Inilah sebabnya mengapa beberapa bentuk elektronik Stetoskop digital telah dikembangkan untuk menggantikan stetoskop akustik konvensional. Pada dasarnya, tujuan digital stetoskop adalah untuk memperbaiki resolusi suara, memungkinkan amplifikasi variabel, meminimalkan gangguan dan menyederhanakannya sinyal output. Stetoskop elektronik terdiri dari membran dan selang dari stetoskop konvensional ditambah dengan mic kondensor yang kemudian terhubung dengan PC melalui soundcard [3]. Sebelumnya telah dibuat penelitian oleh Fardhon Danang Prakoso (2018) dengan judul Jantung Dan Paru Berbasis Wireless. Penelitian tersebut melakukan pembacaan data sinyal suara jantung dan paru dengan menggunakan PC, sehingga alat masih membutuhkan PC dalam pengoperasian. Kelemahan alat dalam menggunakan PC adalah apabila melakukan pemeriksaan dengan menampilkan sinyal suara jantung maka harus tersedianya PC.

Berdasarkan dari masalah diatas, maka penulis akan membuat Stetoskop Elektronik untuk Auskultasi Jantung dengan Tampilan TFT. Penulis ingin melakukan pengembangan alat dengan tampil sinyal pada TFT sehingga alat dapat bersifat portable yang memudahkan dalam penggunaan yang tidak memerlukan PC dan menggunakan baterai charge, namun ancaman yang harus dihadapi yaitu sudah adanya alat stetoskop elektronik yang lebih kompleks dan lebih simple seperti buatan pabrikan yang terbaru..

\section{BAHAN DAN METODE}

\section{A. Rancangan Percobaan}

Percobaan dilakukan oleh responden laki-laki dengan umur 19 - 25 tahun. Dilakukan secara acak dan sejumlah 5 kali percobaan .

\section{1) Alat Dan Bahan}

Penelitian ini menggunakan Chestpiece dari Stetoskop (OneMed, Jayamas Medical Industri, Indonesia). Chestpiece dipasang pada dada sebelah kiri. Penguat instrumentasi dibangun berdasarkan LM324 OP-AMP. Minimum System ATMega 2560 digunakan untuk proses menampilkan sinyal pada TFT nextion dan nilai bpm. Menggunakan TFT merk 
Nextion dengan spesidikasi 2,4 inch. Oscilloscope penyimpanan digital (Textronic, DPO2012, Taiwan) digunakan untuk menguji rangkaian analog.

\section{2) Percobaan}

Dalam penelitian ini, setelah desain selesai maka respons frekuensi perangkat ini diuji menggunakan function generator sesuai dengan spesifikasi sinyal suara jantung. Untuk nilai BPM, akan dibandingkan pada nilai BPM ala Pulse Oxymeter. Setiap pengaturan, output Holter dihitung untuk validasi hasil penelitian ini. Kemudian Holter diuji pada tubuh manusia.

\section{B. Diagram Blok}

Suara jantung akan disadap oleh stetoskop melalui mic kondensor. Mic kondensor mengubah suara menjadi listrik yang akan di kuatkan melalui rangkaian Pre-Amp dengan nilai penguatan yang telah disesuaikan. Output dari Pre-Amp masuk ke rangkaian filter sehingga dapat menyaring frekuensi suara yang dibutuhkan. Dikarenakan melawati filter, maka akan dikuatkan lagi dengan rangkaian gain dengan penguatan yang telah disesuaikan terlebih dahulu selain itu, dari rangkaian filter masuk ke Bluetooth Transmitter yang selanjutnya akan diteruskan pada headset bluetooth untuk output suara jantung. Setelah dikuatkan, sinyal masuk ke mikrokontroller untuk diolah. Suara dan sinyal lalu ditampilkan melalui speaker dan TFT.

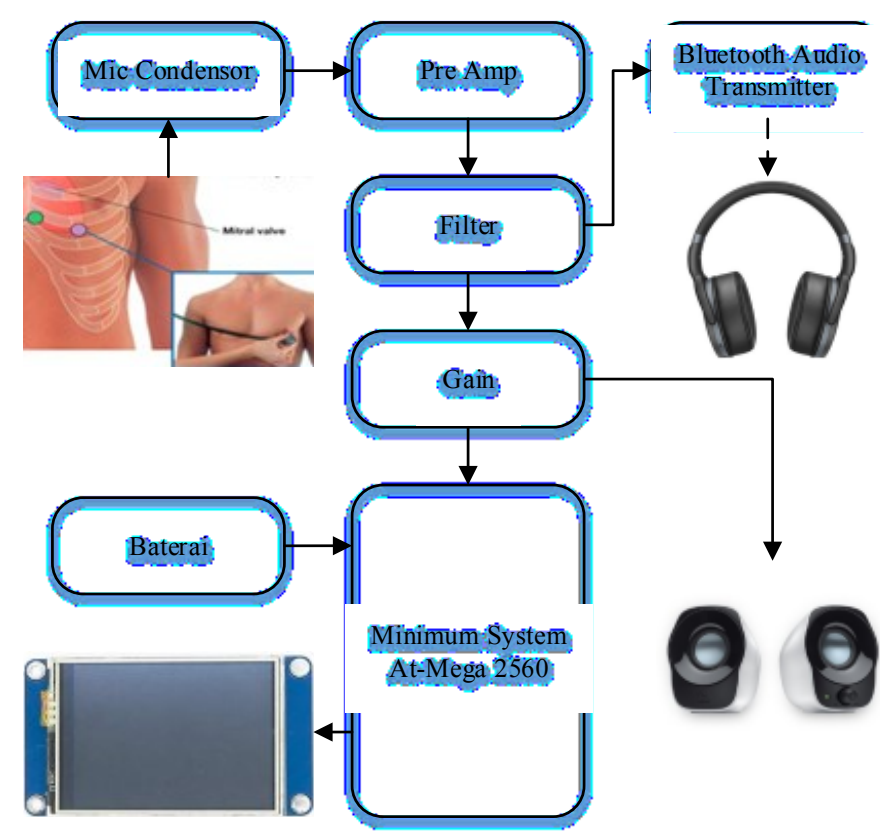

Gambar 1. Diagram Blok Stetoskop Elektronik Portabel

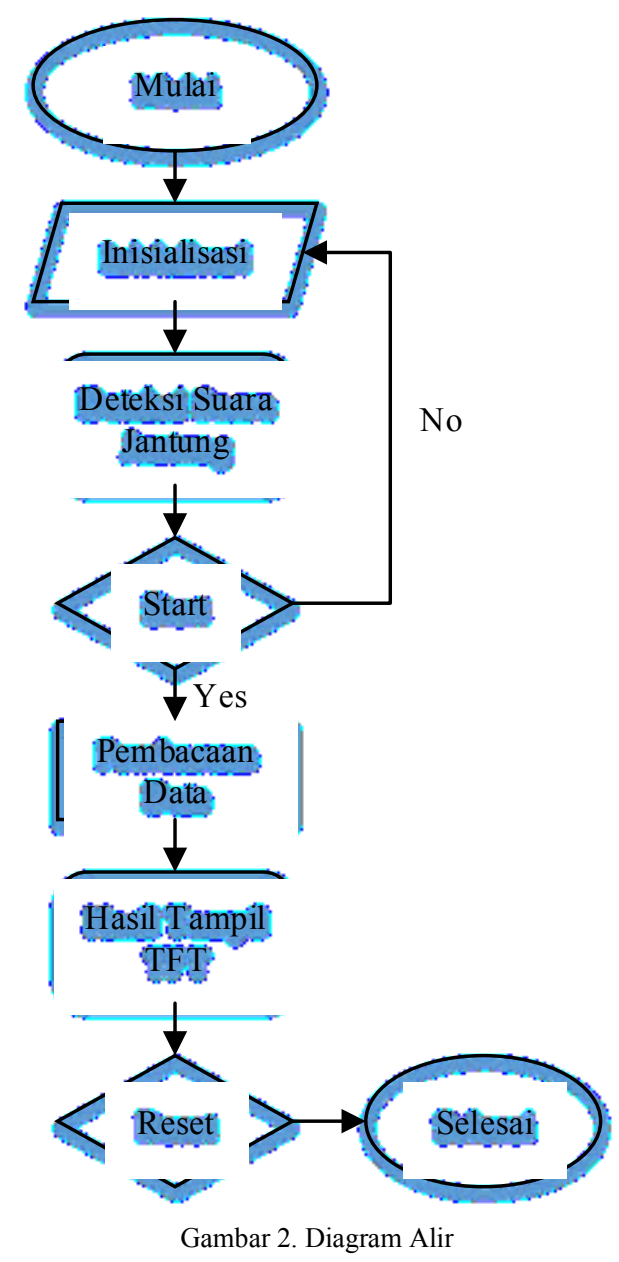

C. Diagram Alir

Menggunakan Minimum System AtMega2560, ditunjukkan pada Gambar 2. flowchart diawali dengan inisialisasi program. Setelah inisialisasi, maka program akan bisa dimulai jika dapat mendeteksi suara jantung. Jika ditekan start maka program akan membaca data dan akan ditampilkan pada TFT.

\section{Rangkaian Analog}

Bagian Paling penting pada perancangan ini adalah rangkaian analog yang dijelaskan di Gambar. 3 (Pre-Amp), Gambar. 4 (HPF-LPF filter), Gambar. 5 (Gain), and Gambar. 6 (Adder). Rangkaian ini digunakan unutuk memproses sinyal suara jantung. Oleh karena itu perlu minimum system untuk memproses menjadi sinyal digital.

\section{1) Preamplifier}

Penguat Awal (Preamplifier) seperti yang terlihat pada Gambar. 3 merupakan part rangkaian yang penting untuk proses analog. Rangkaian ini menggunakan dual OP-AMP dan untuk input tegangan pada Op-Amp ini menggunakan +5 dan -5 VDC. Penguatan awal diatur oleh R6 (22K ohm) dan R5 (1K ohm) sehingga penguatan sesuai rumus yaitu sebesar 22 kali seperti pada Gambar 3. 


$$
\text { Gain }=\frac{R 6}{R 5}
$$

Dimana $\mathrm{R}_{6}$ merupakan resistor feedback, $\mathrm{R} 5$ merupakan resistor pembagi dan penguatan tergantung pada perhitungan rangkaian.

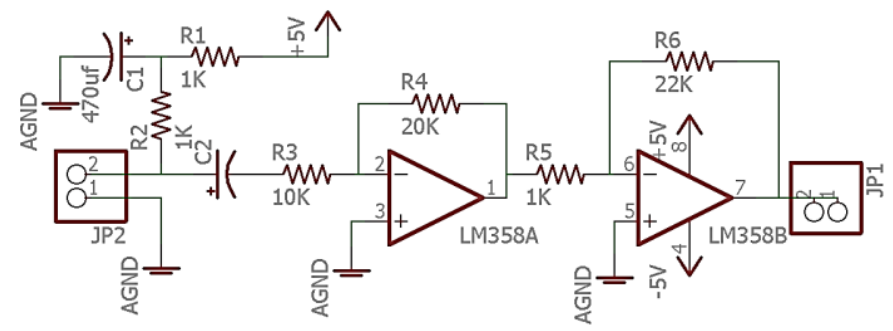

Gambar 3. Penguat Awal (Pre-Amp)

\section{2) $H P F-L P F$ Filter}

HPF-LPF filter digunakan untuk pembatas dan penyaring frekuaensi sinyal suara jantung.

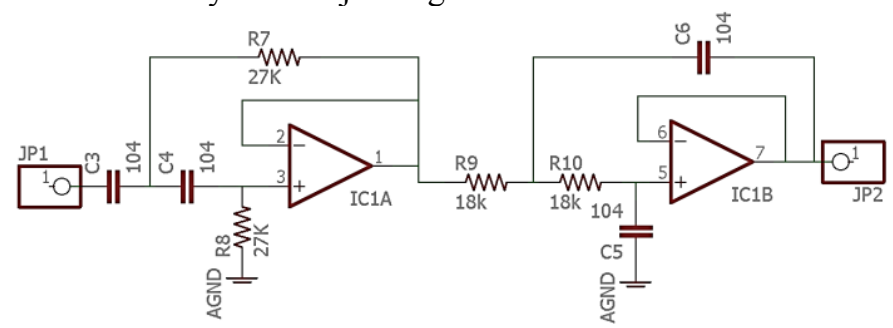

Gambar 4. HPF-LPF Filter

HPF-LPF filter didesain dengan range cut off sebesar 55 sampai $90 \mathrm{~Hz}$. Untuk input tegangan pada Op-Amp ini menggunakan +5 dan -5 VDC, diharapkan Op-Amp dapat bekerja dengan baik. Fungsi kapasitor dan resistor di atas untuk menentukan nilai frekuensi cut off yang ingin dicari

$$
f c=\frac{1}{2 \pi R C}
$$

dimana $\mathrm{R}$ merupakan nilai resitansi, $\mathrm{C}$ merupakan nilai kapasitansi, and fc adalah nilai frekuensi cut off dari perhitungan.

\section{3) Gain}

Pada rangkaian gain ini digunakan Op-Amp 324, dimana IC tersebut memiliki 4 Op-Amp didalamnya. Untuk input tegangan pada Op-Amp ini menggunakan +5 dan -5 VDC, diharapkan Op-Amp dapat bekerja dengan baik. Penguatan terjadi 4,7 kali. Perbandingan nilai resistor di atas untuk menentukan besar pengali penguatan yang diinginkan seperti Gambar. 5. Perhitungan besar pengali pada rangkaian gain :

$$
A=\frac{R 12}{R 11}
$$

dimana R12 merupakan resistor feedback, R11 merupakan nilai resistor pembagi dan penguatan tergantung pada perhitungan rangkaian.

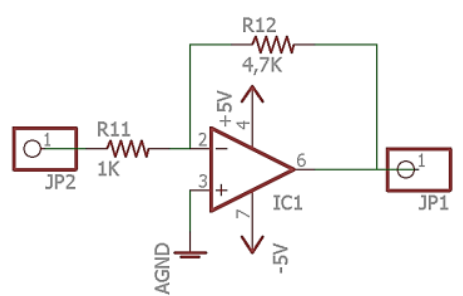

Gambar 5. Rangkaian Gain.

\section{4) Rangkaian Adder}

Rangkaian adder digunakan untuk mengatur referensi sinyal yang diproses oleh minimum system. Menggunakan resistor variabel untuk mengatur pembagi tegangan pada Gambar. 6 pada sinyal suara jantung yang tampil pada layar TFT.

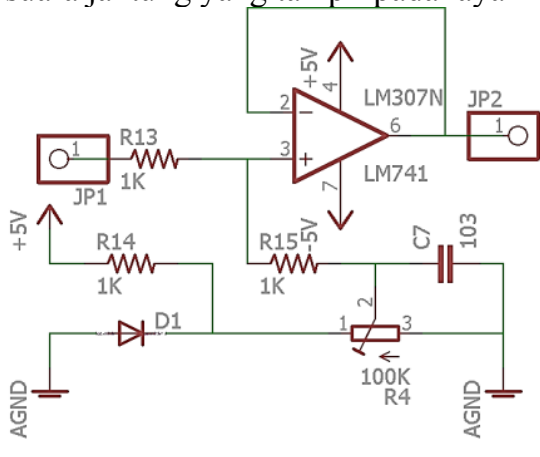

Gambar 6. Rangkaian Adder

5) Minimum System AtMega 2560

Minimum System menggunakan Tegangan +5 dan ground. IC Mikrokontroller yang digunakan adalah Atmega 2560. Membutuhkan port RX, TX dan Reset untuk dapat memprogram Atmega 2560. Menghubungkan port analog sebagai masukan untuk mengolah plotting sinyal suara jantung dan nilai bpm yang tampil pada TFT. Menghubungkan Vcc, Ground, RX, dan TX sebagai output ke TFT sebagai tampilan. Gambar. 7.

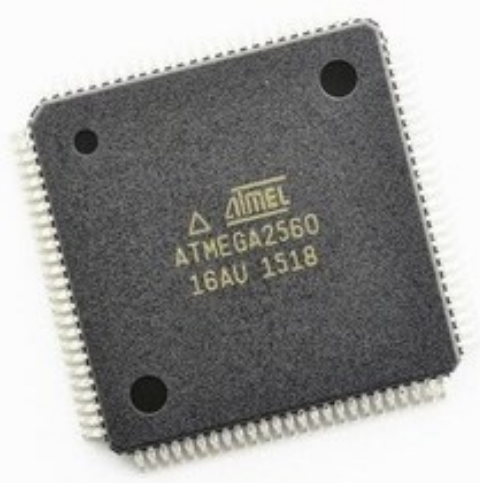

Gambar 7. At Mega 2560 


\section{Pembahasan}

Dalam penelitian ini, Stetoskop telah dibandingkan menggunakan Pulse Oxymeter dari tubuh manusia. Hasil menunjukkan bahwa perekaman layak untuk merekam sinyal suara jantung dan nilai BPM dari tubuh manusia.

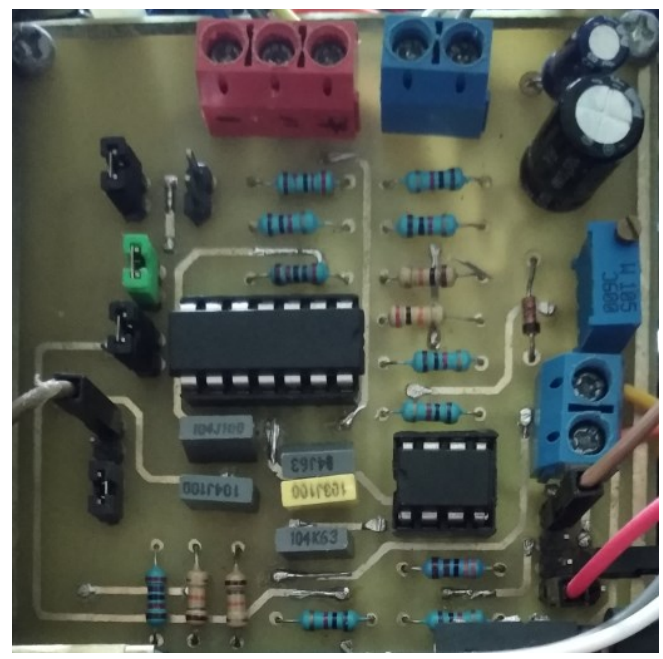

Gambar 8. Rangkaian Analog

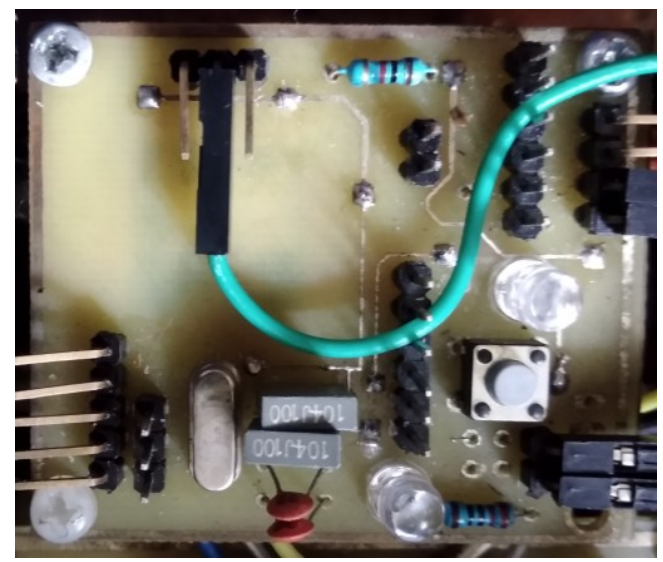

Gambar 9. Minimum System

1) Desain Stetoskop Elektronik Portable

Foto bagian analog dan minimum system dari Stetoskop Elektronik Portable ditunjukkan pada Gambar. 8 and Gambar. 9, Foto bagian analog dan digital dari Holter ECG ditunjukkan pada Bagian analog terdiri dari LM324 dan LM358 (OP-AMP) yang masing-masing unit terdiri dari empat dan dua OP-AMP. Terdapat Multiturn 100K juga yang berfungsi sebagai pembagi tegangan untuk mengatur refrensi sinyal pada tampilan TFT nextion. Menggunakan IC ATMega2560 sebagai papan utama Stetoskop Elektronik Portable serta beberapa modul lainnya seperti modul Bluetooth Audio Transmitter yang berfungsi untuk mengirim suara pada Headset Bluetooth dan juga TFT Nextion sebagai tampilan sinyal suara jantung.
2) Listing Program untuk Stetoskop Elektronik Portable Pada penelitian ini menggunakan minimum system AtMega 2560 dan program melalui arduino. Untuk program pada arduino ditujukan pada listing program 1. Yang terdiri dari program untuk membaca dan menampilkan sinyal suara jantung dan nilai BPM pada layar tauchscreen TFT Nextion.

Listing program 1. Inisialisasi Program

//============-inisialisasi $==============/ /$
\#include $<$ SoftwareSerial.h $>$
\#include "Nextion.h"
\#include $<$ NexText.h $>$
\#include $<$ NexNumber.h $>$
\#define waktusensor 10
uint32_t tsLastReport1 =0;
unsigned long waktuBPM,waktusekarang,waktu,
waktureset, wakturesetnow, resetbpm, resetbpmnow;
unsigned long int waktuawal;
float ref,hold,tegangan,BPMpalsu=0;
int BPMasli, koreksibpm, bpmtanda $=0 ;$
int bpmne;
int b=0;
unsigned int dataadc;

\section{3) Setting Baudrate pada layar TFT Nextion}

Dalam modul stetoskop portable menggunakan layar touchscreen TFT nextion untuk menampilkan plot sinyal suara jantung. Dalam menampilkan sinyal pada TFT nextion perlu mengatur baudrate untuk menyesuaikan tampilan sinyalnya. Seperti yang ditujukan pada Listing Program 2.

Listing Program 2. Program setting baudrate untuk menampilkan plot suara jantung pada TFT nextion.

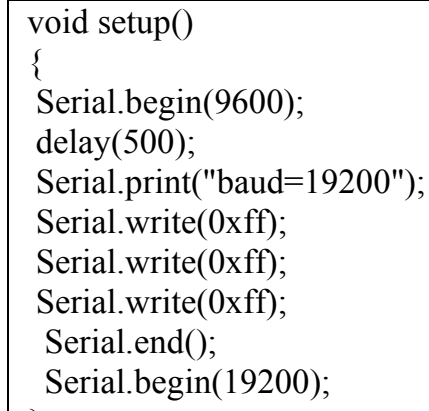

4) Menentukan perhitungan untuk menampilkan nilai bpm Pada saat menghitung nilai bpm pada modul stetoskop portable maka diperlukan referensi yang digunakan untuk membatasi satu kali pembacaan dalam menghitung 1 kali detak jantung. 
Listing Program 3. Program menentukan batas sebagai auto refrensi untuk menampilkan nilai bpm

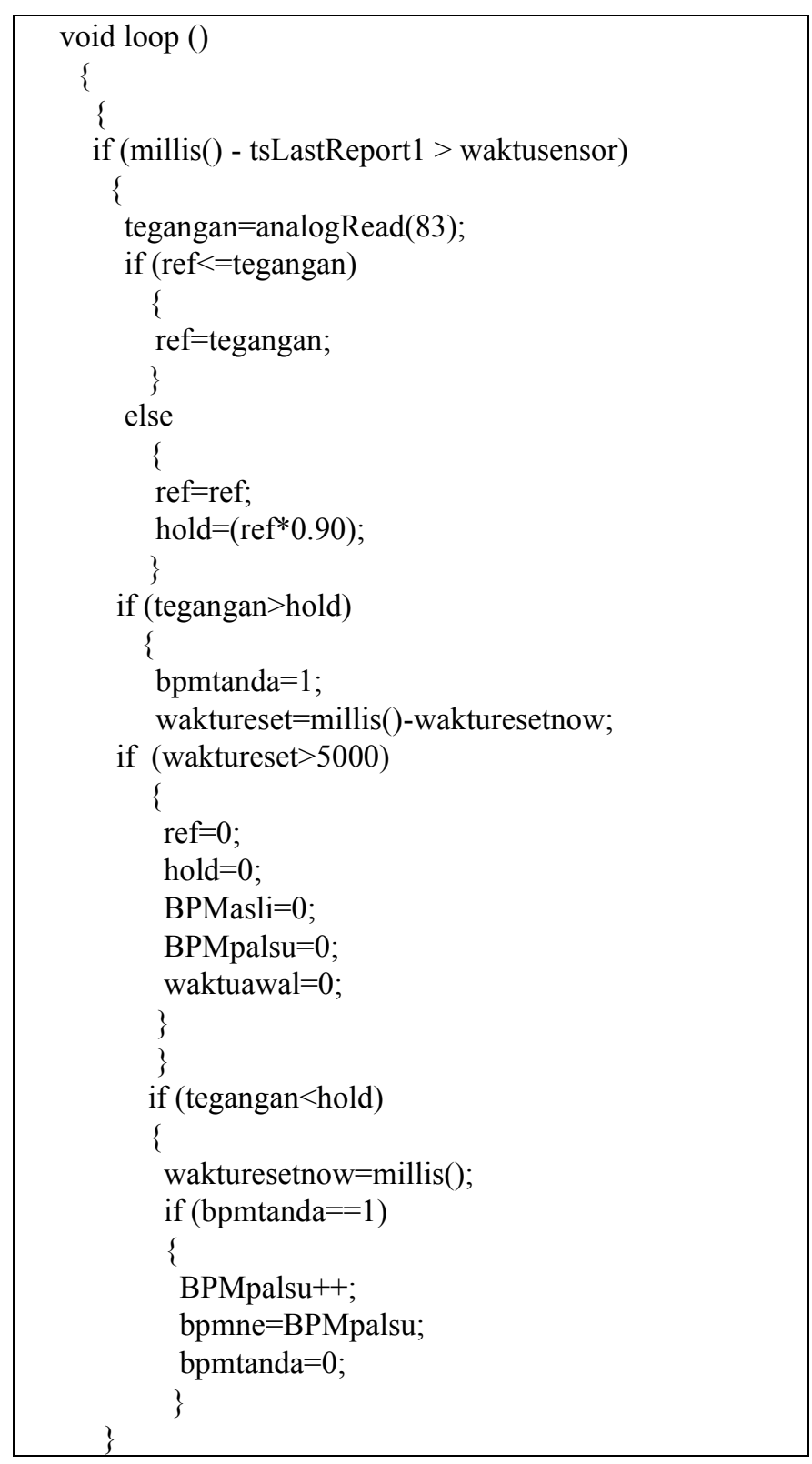

Dalam menampilkan nilai bpm diperlukan waktu yang dihitung dari mulai detak pertama hingga detak kesepuluh. Waktu yang ditempuh itu akan diproses dalam rumus program untuk menentukan nilai BPM.

Listing Program 4. Program untuk waktu tiap perubahan pembacaan bpm

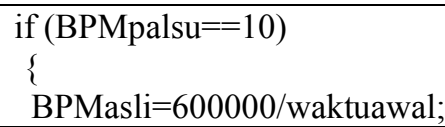

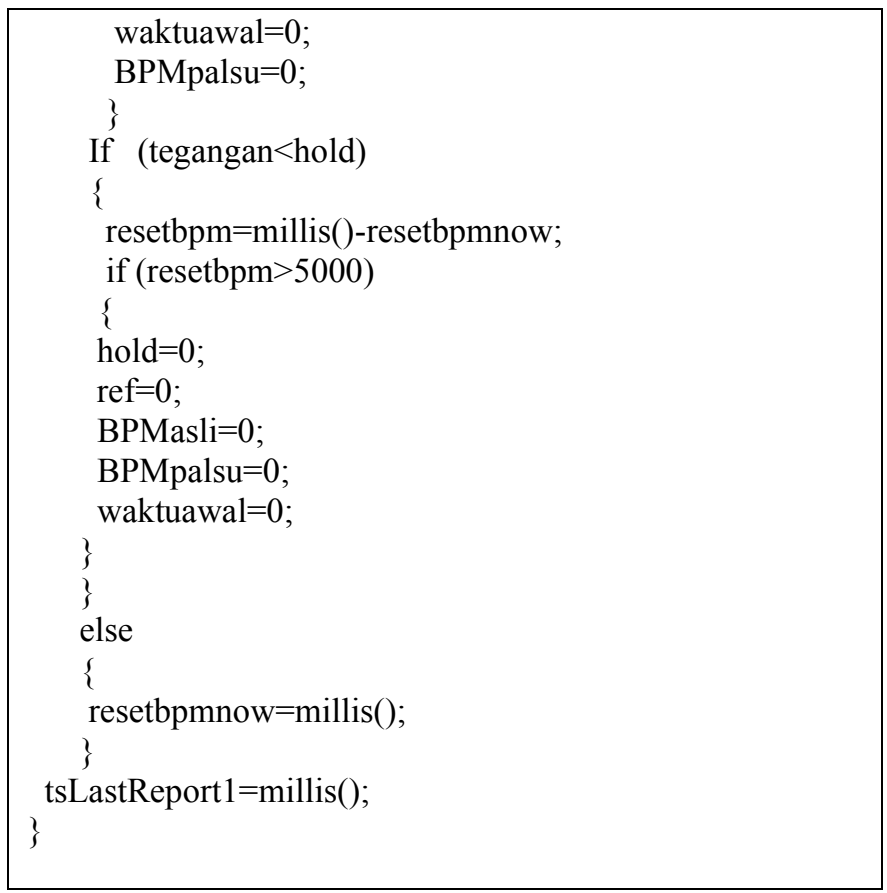

The Listing Program 5. Digunakan untuk menampilkan nilai bpm pada layar TFT nextion. Pada inisial n1 berfungsi menampilkan nilai tiap detak, sedangkan pada n0 digunakan untuk menampilkan Nilai BPM.

Listing Program 5. Program to save the ECG data to file

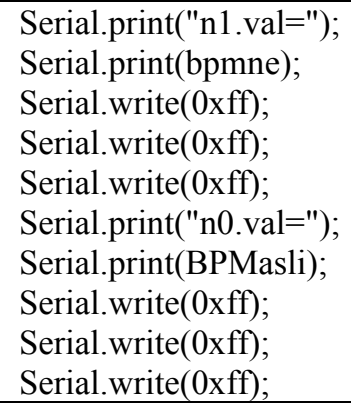

Untuk mengkonversi menjadi bentuk sinyal suara jantung pada layar TFT nextion ditunjukkan pada listing program 6 .

Listing Program 6. Program menampilkan plotting sinyal suara jantung pada TFT nextion

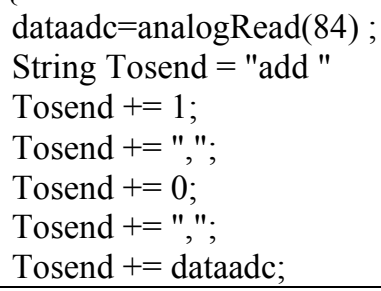




\section{Serial.print(Tosend);}

Serial.write(0xff);

Serial.write(0xff);

Serial.write(0xff);

\}

;

5) Nilai error BPM (Beats Per Minutes)

Validasi nilai BPM yang tampil pada layar TFT nextion dibandingkan dengan alat pulse Oximetry. Diperoleh nilai error seperti Tabel I.

TABLE I. ERROR NILAI BPM PADA MODUL DENGAN ALAT STANDART (PULSE OXIMETRY).

\begin{tabular}{ccc}
\hline No & Subject & Error $(\%)$ \\
\hline 1 & P1 & $0,52 \%$ \\
2 & P2 & $0,72 \%$ \\
3 & P3 & $0,64 \%$ \\
4 & P4 & $0,67 \%$ \\
5 & P5 & $0,46 \%$ \\
\hline
\end{tabular}

Pengukuran nilai BPM dalam sinyal suara jantung dari tubuh manusia juga dibandingkan dalam penelitian ini, antara desain stetoskop elektronik portable dan pulse oximeter. Hasilnya ditunjukkan pada Tabel 1 .

\section{DISKUS}

Desain penelitian Stetoskop elektronik Portable ini telah diuji dan diukur output rangkaian dengan menggunakan osiloskop. Dan untuk pembanding nilai bpm menggunakan alat Pulse Oxymeter. Untuk pengukuran mengunakan media tubuh manusia. Pada saat pengukuran, pasien yang diperiksa menggunakan modul stetoskop harus dalam kondisi tenang karena dapat mempengaruhi nilai bpm yang terdeteksi pada alat. Pengukuran dilakukan oleh 5 pasien dan membandingkan dengan alat pulse oxymeter. Nilai error yang dihasilkan oleh alat sekitar $<1 \%$ sehingga dibawah dari ketentuan error BPM yang ditetapkan oleh BPFK.

\section{KESIMPULAN}

Studi ini telah menunjukkan perkembangan stetoskop untuk memantau suara dan sinyal jantung dari subjek secara real time. Studi ini dibangun berdasarkan mikrokontroler Arduino dan beberapa rangkaian analog serta dtampilkan pada layar TFT nextion. Pada modul ini menggunakan 2 output suara yaitu menggunakan headset bluetooth dan juga speaker aktif. Studi ini telah membuktikan bahwa keakuratannya layak digunakan untuk memantau sinyal suara jantung secara real time dan bersifat portable dengan tampilan layar touchscreen. Di masa depan, penelitian ini dapat dibuat dan digunakan di klinik kecil di desa-desa dengan biaya rendah.

\section{RERERENS}

[1] I. D. Gede and H. Wisana, "Design Electronic Stethoscope for Cardiac Auscultation analyzed using Wavelet Decomposition," vol. 1, no. 7, pp. 310-315, 2013.

[2] M. Pascasarjana, J. Teknik, and T. Informasi, "Reduksi Suara Jantung Dari Instrumentasi Akuisisi Perekaman Suara Paru-Paru Pada Anak-Anak Menggunakan Butterworth Band Pass Filter", Skripsi, Jurusan Teknik Elektrodan Teknologi Informasi UGM Jalan Grafika No 2 Kampus UGM Yogyakarta, 14 Desember 2013 E 130," pp. 129-134, 2013.

[3] E. Budiasih, A. Rizal, and S. Sabril, "Hardware Dan Software Analisis Auskultasi Konferensi Nasional Sistem Informasi 2011,” pp. 287-291, 2011.

[4] M. F. Syahputra, R. F. Rahmat, and J. A. Sitepu, "Visualisasi Suara Jantung Manusia Pada Platform Mobile,” vol. 15, pp. 66-72, 2015.

[5] J. T. Elektro and P. N. Semarang, "Rancang Bangun Stetoskop Digital," vol. 9, no. 1, pp. 36-42, 2013. 